\title{
Crecientes niveles de producción y consumo de leche en China
}

DOI: $10.32870 /$ mycp.v13i39.351

Ramón Robledo Padilla ${ }^{1}$

\section{Resumen}

$\mathrm{E}$ ste artículo analiza las razones del crecimiento en la producción y consumo de leche en China en los últimos años, así como el impacto que esto podría tener en el incremento de los precios internacionales de los lácteos. También se señala que dicho crecimiento en los precios sería perjudicial para los productores de países que son importadores netos de leche, como es el caso de México.

Palabras clave: China, leche, producción, consumo.

\section{Abstract}

This article analyzes the reasons for the growth of milk production and consumption in China in the last years, as well as the impact this might have on the international price of dairy products. Such impact could have deleterious effects on countries which are milk net importers, such as Mexico.

Keywords: China, milk, production, consumption.

\section{Introducción}

En los últimos años, y muy particularmente desde la década de 1990, en China se ha detectado un crecimiento significativo en la demanda de leche bovina y algunos de sus derivados como son: la leche en polvo, suero, yogurt, queso

1. Profesor-Investigador del Departamento de Estudios del Pacífico, Centro Universitario de Ciencias Sociales y Humanidades, Universidad de Guadalajara. 
y mantequilla, entre otros. Dicho crecimiento se debe a varias razones, entre las cuales destacan el incremento en el consumo debido al creciente nivel de ingresos de la población, sobre todo en zonas urbanas; la activa participación del gobierno enfocada a incrementar la producción y el consumo de leche en el país, y finalmente, la mayor información a través de algunos medios de comunicación, los cuales difunden que el consumo de leche es benéfico para la salud. Lo anterior es relevante dado que, por el tamaño de la población de China, un incremento sostenido en su consumo de lácteos como el que se ha mostrado en años recientes, podría provocar un incremento importante en los precios internacionales de la leche, e ir en contra de los intereses de los países que son importadores netos de leche, como es el caso de México.

\section{Producción}

En China se produce casi de todas las leches que suelen producirse y/o consumirse en algunas partes del mundo, como la de búfala, cabra, camella, bovino y de oveja. Sin embargo, a nivel mundial, la leche que más se produce es la de bovino, la cual representa poco más de $80 \%$ de toda la leche producida. Por ejemplo, en 2007 se produjeron en todo el mundo 679 mil millones de litros de leche, $83 \%$ correspondió a leche de vaca, $12 \%$ fue de búfala, $2 \%$ de cabra, y poco más de $1 \%$ de oveja. En este escenario mundial, China ocupa el primer lugar en la producción de leche de oveja que, como vimos, a escala internacional representa la cuarta posición, con una producción de poco más de 9 mil millones de litros.

\section{Cuadro 1}

Producción mundial de leche (millones de litros)

\begin{tabular}{lrrrrrr}
\hline País & \multicolumn{1}{c}{2000} & \multicolumn{1}{c}{2003} & \multicolumn{1}{c}{2004} & \multicolumn{1}{c}{2005} & \multicolumn{1}{c}{2006} & \multicolumn{1}{c}{2007} \\
\hline China & 8,632 & 17,817 & 22,928 & 27,837 & 32,257 & 35,574 \\
India & 32,967 & 34,973 & 37,344 & 39,759 & 41,400 & 42,890 \\
Nueva Zelanda & 12,223 & 14,349 & 15,030 & 14,637 & 15,332 & 15,841 \\
Australia & 11,183 & 10,075 & 10,125 & 10,089 & 9,583 & 9,223 \\
Unión Europea & 150,717 & 150,406 & 148,255 & 149,269 & 148,290 & 148,028 \\
Estados Unidos & 76,023 & 77,289 & 77,535 & 80,254 & 82,463 & 84,189 \\
México & 9,311 & 9,784 & 9,864 & 9,868 & 10,088 & 10,345 \\
Mundo & 490,670 & 518,437 & 528,098 & 543,964 & 557,431 & 566,850 \\
\hline
\end{tabular}

Fuente: http://www.fao.org 
No obstante que China produce casi de todas las leches que se producen en el mundo, es en la de bovino donde se han presentado cambios muy importantes en la producción de leche. Estos cambios comenzaron a ser muy significativos a partir de los años noventa y se aceleraron después del año 2000. De acuerdo a datos de la FAO (Food and Agriculture Organization, que es la Organización de las Naciones Unidas para la Agricultura y la Alimentación) de 1990 a 2000, la producción de leche bovina tuvo un crecimiento promedio anual de $7 \%$, lo que quiere decir, que en todo el periodo tuvo un aumento de $97 \%$ en la producción, al pasar de 4,362 a 8,632 millones de litros; pero en lo que va del año 2000 al 2007, es decir, en siete años, el crecimiento fue de $312 \%$, es decir, su crecimiento promedio anual se triplicó al pasar de $7 \%$ a $22 \%$, por lo cual se registró un incremento en la producción de 8,632 a 35,574 millones de litros. En contraste con estos incrementos en la producción de leche bovina, en lo que se refiere a la producción de las otras leches, el crecimiento promedio anual de 2000 a 2007 ha disminuido con respecto al mostrado en los años noventa. Por ejemplo, en la producción de leche de búfala, en la década de los noventa se registró un incremento promedio anual de $3.3 \%$, y en los siguientes siete años de 2000 a 2007, el crecimiento se redujo a 1.2\%, lo mismo sucedió con la producción de leche de oveja y de cabra, las cuales habían registrado de 1990 a 2000 un incremento porcentual promedio anual de 3.5 y 3.3 respectivamente, y en los siguientes siete años disminuyeron; en el caso de la leche de oveja a 3.3 y en el de la leche de cabra a $1.7 \%$ promedio anual. En cuanto a la producción de leche de camella, ésta prácticamente se ha mantenido en todos estos años en 14 millones de litros. Todos estos cambios en la producción interna, al final de cuentas se vieron reflejados en un incremento en la participación relativa de la producción de leche bovina y una disminución en dicha participación de las otras leches. Así, tenemos que en 1990, la participación de la leche bovina en el total de la producción en China era de $62 \%$ y en 2007 fue de $89 \%$, la de búfala pasó de $27 \%$ a $7 \%$, la de oveja de $8 \%$ a $3 \%$ y finalmente la de cabra que pasó de $2 \%$ a $1 \%$.

Una de las características que distinguen la producción de leche bovina en China es que ésta se encuentra muy concentrada en algunas regiones, sobre todo donde abundan los pastos y en las áreas muy urbanizadas. Por ejemplo, en los lugares altamente urbanizados como Pekín, Tianjin y Shanghai, en 1999 se registró $9 \%$ de la producción total de leche en China; en cambio, entre las provincias más importantes para la producción por sus pastos abundantes, se encuentran Heilongjiang, Hebei y Mongolia, las dos últimas localizadas en 


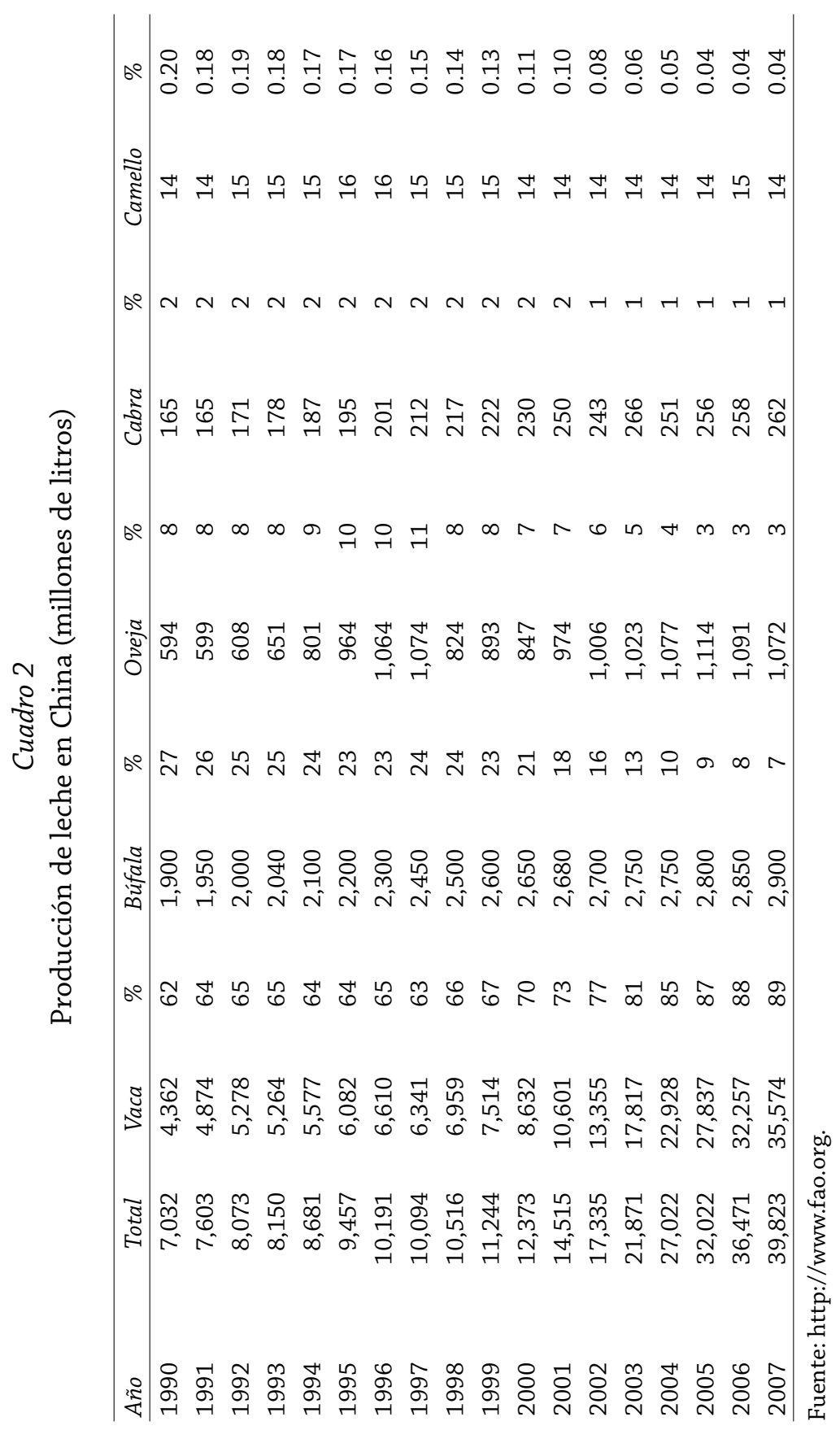


la región nordeste de China. Heilongjiang también es conocida como la tierra de la leche, debido a que es donde se produce la mayor cantidad. En 1997, por ejemplo, se registró 25\% de la producción nacional; sin embargo, en 1999 redujo su participación a $18 \%$ debido a varias inundaciones que se presentaron en 1998 y provocaron que el hato ganadero disminuyera de 850,000 a 680,000 cabezas. Junto con Hebei y Mongolia, estas tres provincias participaron en 1999 con $36.6 \%$ de la producción total del país. ${ }^{2}$

\section{Mapa de China}

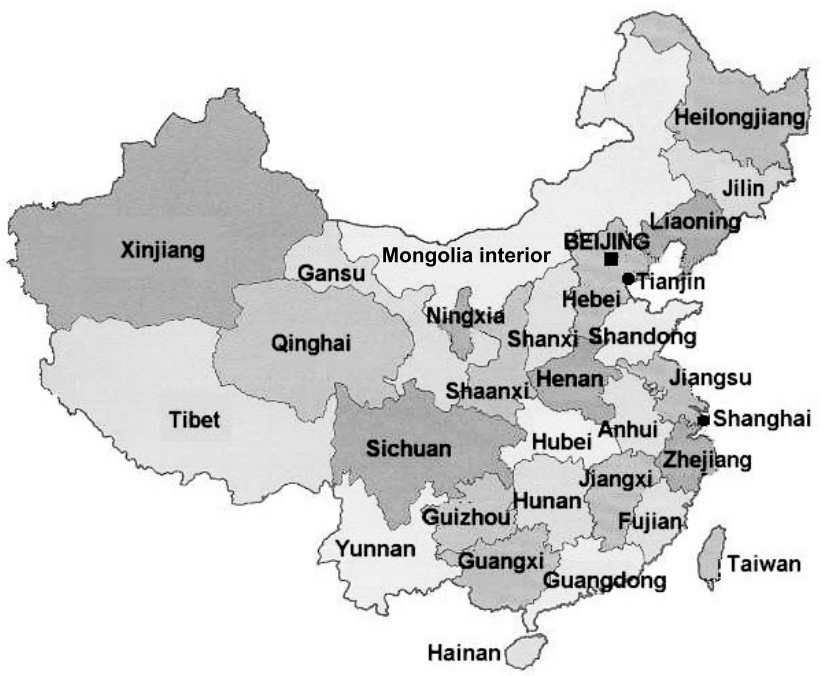

Fuente: http://blog.educastur.es/aulainmersionaviles/2008/12/

La producción de leche es también importante en algunas provincias altamente pobladas como Shaanxi y Sicuani, donde en el mismo año de 1999 se produjo $6.9 \%$ y $3.9 \%$, respectivamente. En las provincias de occidente donde hay abundantes pastos, en especial la de Xinjiang, se produjo $8.7 \%$ del total. En contraste, la producción de leche es insignificante en las regiones intensivas en la producción de cereales, como las tierras bajas del este y sudeste de China; estas provincias contribuyeron a la producción de leche entre $1 \%$

2. Wattiaux, Michel A., Gary G. Frank, J. Mark Powell, Zhiguo Wu y Yuyuan Guo, "Agriculture and dairy production systems in China: an overview and case studies", en: http://babcock. cals.wisc.edu/downloads/dp/2002-3-color.en.pdf, 2002-2003, p. 23. 
y menos de $1 \%$ del total nacional. ${ }^{3}$ Además de las regiones que destacan en la producción de leche, en general, en China se distinguen básicamente tres sistemas de producción, los que se dan en áreas de abundantes pastos, en áreas de cultivos y en zonas urbanas. ${ }^{4}$

\section{Sistema de producción pastoral}

Los lugares donde abundan los pastos en China, están localizados en Inner Mongolia, Xinjiang, Tibet, Gansu y Heilongjiang, donde los residentes pertenecen a minorías étnicas principalmente. La cría de animales es la principal actividad en estas zonas de clima severo y baja densidad de la población. Con respecto a la producción de leche, una gran parte de la misma se destina al autoconsumo y al cuidado de los animales jóvenes, excepto en Heilongjiang.

Algunas firmas procesadoras de leche han comenzado a establecer bases de producción de leche cruda en lugares seleccionados donde la oferta de alimento es abundante y el ambiente está relativamente descontaminado. Heilongjiang e Inner Mongolia lideran este desarrollo y se han convertido en los productores y procesadores más grandes de China.

Sistema de producción en áreas de cultivo

Este sistema de producción está caracterizado por sus bajos costos en mano de obra y alimentación. Debido a la muy baja disponibilidad de la tierra, los granjeros crían animales principalmente en corrales. La leche es a veces un subproducto de la producción de becerros y la escala de la producción de la leche es baja, sin embargo está orientada principalmente al mercado, como en los casos de Jiangsu, Jiangxi y Guangdong.

Sistema de producción en áreas suburbanas

La demanda de productos lácteos está concentrada principalmente en las grandes ciudades y los consumidores tienen fuertes preferencias por la leche

3. Ibídem, pp. 23 y 24.

4. Zhang-Yue Zhou, Wei-Ming Tian y Jun-Lin Zhou, "The emerging dairy economy in China: production, consumption and trade prospects", Agribusiness Review, vol. 10, 2002, paper 8, pp. 6 y 8. 
fresca en lugar de otros sustitutos de la leche reconstituidos, como por ejemplo la leche de soya. Esta demanda ha estimulado el desarrollo de la producción de leche en zonas suburbanas de las grandes ciudades, y a su vez, ha permitido superar la falta de trasporte en frío, necesario para evitar la descomposición de la leche.

Los rasgos de la producción en estas áreas son los siguientes: la escala es relativamente alta, con rendimientos por unidad animal altos, uso intensivo de alimentos, producción con orientación de mercado y un alto grado de integración vertical. La leche producida se vende a industriales quienes, a su vez, la ofrecen al consumidor mediante productos elaborados con el respaldo de cierta marca, como sucede por ejemplo en la ciudad de Beijing.

El desarrollo de la producción de leche en zonas urbanas también ha sido estimulado por el gobierno mediante algunos programas como el "Food Basket Project" (Proyecto de Canasta Alimenticia) y el "School Milk Program" (Programa de Leche Escolar), por medio de los cuales, se pretendió que cada vez más, un mayor número de personas consumiera leche de manera regular.

La producción y oferta de leche en áreas suburbanas tradicionalmente había sido realizada por el Estado y por granjas colectivas. Sin embargo, debido al crecimiento de la demanda y con el fin de expandir los negocios, muchas empresas procesadoras comenzaron a demandar más leche fresca de aquellos productores individuales que se encontraran cercanos a las ciudades, mediante la firma de contratos. Esto permitió un incremento del ganado en muchas de las granjas individuales. No obstante todo lo anterior, se puede decir en general, que el nivel de mecanización para la producción de leche en China es bajo, ninguno de los tres sistemas mencionados utiliza de manera extensiva el uso de ordeñadoras y de equipo de enfriamiento, y en cuanto a la producción comercial, es indispensable la cercanía de los mercados para mantener un mejor control de calidad.

De esta manera, la producción de leche está reducida a ciertas áreas que cuentan con facilidades para el procesamiento y una infraestructura de mercado apropiada, lo cual generalmente sucede en zonas urbanas. Sin embargo, pasado el tiempo y a medida que el valor de la tierra comenzó a incrementarse debido a la escasez en zonas urbanas, paulatinamente se ha dado una tendencia a desplazar la producción de leche de zonas urbanas hacia las áreas de cultivo.

Para tener una idea del despegue tan importante de la producción de leche en China, tenemos por ejemplo, que antes de 1979, la producción de leche bovina no alcanzaba los mil millones de litros por año. Aunque la pro- 
ducción de leche estuvo concentrada en zonas de abundante pasto, algunas empresas se establecieron cerca de las grandes ciudades con el fin de cubrir este mercado. Asimismo, el crecimiento de la propiedad privada de animales fue restringido después de la colectivización agrícola en China iniciada en 1953, por lo cual el Estado y las granjas lecheras colectivas fueron los principales proveedores de leche. En general, la leche líquida y la de polvo eran casi los únicos productos lácteos disponibles y el gobierno otorgaba racionamientos de leche sólo para los niños, personas enfermas y adultas.

Una vez iniciada la reforma económica rural en 1979, la posesión privada de animales fue permitida y la producción estatal y de las granjas colectivas comenzó a crecer a partir de los años ochenta, en respuesta al incremento en la demanda. Además, con el fin de impulsar el sector lácteo, el gobierno comenzó a emprender varias medidas, inclu-

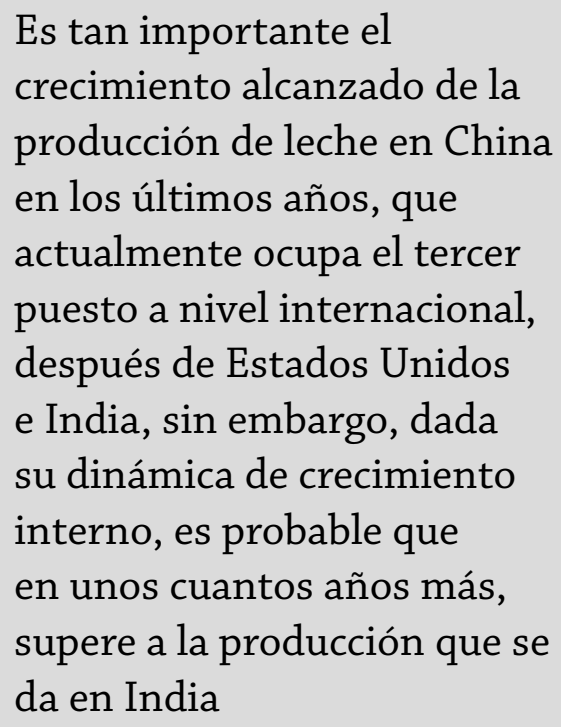
yendo el suministro de préstamos para inversión, subsidio en alimentos, compra de mejores razas de ganado y el suministro de asistencia técnica a productores, así mismo, la inyección de capital extranjero y la introducción de tecnologías avanzadas también promovieron la producción de leche en China. ${ }^{5}$

Es tan importante el crecimiento alcanzado por la producción de leche en China en los últimos años, que actualmente ocupa el tercer puesto a nivel internacional, después de Estados Unidos e India; sin embargo, dada su dinámica de crecimiento interno, es probable que en unos cuantos años más supere a la producción que se da en India. En 2000, por ejemplo, China producía menos leche bovina que México: 8,632 millones de litros contra 9,311 de México; India en cambio, produjo en ese mismo año 32,967 millones de litros. Para

5. Ibídem, pp. 2 у 3. 
2007, China alcanzó la cifra de 35,574 millones de litros contra 42,890 de India y 10,345 de México. Es decir, mientras que el crecimiento porcentual de China en esos siete años fue de $312 \%$, en India fue de $30 \%$ y en México de $11 \%$. Sin embargo, a pesar del logro alcanzado en la producción de leche hasta el momento, el rendimiento por animal sigue siendo muy bajo con respecto a otros países principalmente desarrollados. Por ejemplo en Alemania, en 2007 se produjeron en promedio 6,807 litros por animal, es decir 18.6 litros por día, en Estados Unidos 8,931 y en Canadá 7,730, es decir, 24.4 y 21.1 litros por día respectivamente, y en China en cambio, la producción por bovino fue de 2,863, es decir 7.8 litros por día.

\section{Cuadro 3}

Promedio anual de producción de leche por unidad animal (litros)

\begin{tabular}{llll}
\hline País & 2000 & 2003 & 2007 \\
\hline China & 1,773 & 2,568 & 2,863 \\
Nueva Zelanda & 3,666 & 3,652 & 3,817 \\
Australia & 5,151 & 4,914 & 5,132 \\
Alemania & 6,076 & 6,489 & 6,807 \\
Estados Unidos & 8,036 & 8,262 & 8,931 \\
Canadá & 7,396 & 7,259 & 7,730 \\
México & 3,296 & 3,240 & 3,855 \\
\hline
\end{tabular}

Fuente: www.fao.org

Cuadro 4

Ganado bovino en China

\begin{tabular}{cccc}
\hline Año & Total cabezas & Producción & Productividad \\
\hline & (miles) & (millones de litros) & (litros por día) \\
\hline 1980 & 673 & 1,193 & 4.86 \\
1985 & 1,680 & 2,589 & 4.22 \\
1990 & 2,782 & 4,362 & 4.30 \\
1995 & 3,967 & 6,082 & 4.20 \\
2000 & 4,866 & 8,632 & 4.86 \\
2001 & 4,953 & 10,601 & 5.86 \\
2002 & 5,727 & 13,355 & 6.39 \\
2003 & 6,937 & 17,817 & 7.04 \\
2004 & 8,991 & 22,928 & 6.99 \\
2005 & 11,134 & 27,837 & 6.85 \\
2006 & 12,333 & 32,257 & 7.17 \\
2007 & 12,352 & 35,374 & 7.85 \\
\hline
\end{tabular}

Fuente:http://www.fao.org. 


\section{Consumo}

A pesar del crecimiento tan acelerado en la producción de leche en China en los últimos años, y del incremento en el consumo - sobre todo en algunos sectores de su población, como es el caso en zonas urbanas-, si se compara con otros países, el consumo per cápita continúa siendo muy bajo. Por ejemplo, donde más se consume leche es en los países desarrollados como Canadá, Estados Unidos, Francia, Alemania etc., en cambio en Asia el consumo de leche es mucho más bajo. En 2007, mientras que en los primeros el consumo anual de leche bovina osciló entre 200 y 300 litros per cápita, en China se consumieron alrededor de 20 litros. $^{6}$

Históricamente, el hábito de ingerir leche y sus derivados ha sido muy escaso en China debido a varias razones: el índice elevado de intolerancia a la lactosa (casi $80 \%$ de la población presentaba este síntoma a la edad de ocho años), ${ }^{7}$ el bajo nivel de producción de leche comparado con el tamaño de su población; inconvenientes como el clima, la falta de transporte y de almacenes adecuados. Sin embargo, pese a todos estos inconvenientes, desde hace 25 años, particularmente durante la última década del siglo xx, los patrones de consumo en China han ido cambiando, ${ }^{8}$ en especial en las áreas urbanas, donde los ingresos de la población en promedio son mayores. En estos lugares, siguiendo la tendencia de los hábitos de consumo de los países ricos, conforme se incrementan los ingresos, cada vez se consumen más los productos de origen animal, como la carne de carnero, cerdo, res y ave, además del huevo y la leche. Otra característica importante es que los lácteos en China, a excepción de los otros productos mencionados, presentan características de un bien de lujo, debido a que tiene una elasticidad ingreso de la demanda de $1.26,{ }^{9}$ es decir, mayor que uno; en cambio los otros cinco bienes están dentro de los considerados como necesarios porque sus elasticidades son menores a uno. ${ }^{10}$

6. http://www.fao.org.

7. Goodland, Robert, "The westernization of diets: the assessment of impacts in developing countries- with special referent to China", en: http://www.globalhunger.net/GoodlandChina. pdf, 2001, p. 22.

8. Wattiaux, Michel A., op. cit., p. 25.

9. Ma, Hengyun y Allan Rae, "Projections of dairy product consumption and trade opportunities in China", China Agriculture Working Paper 2003, Centre for Applied Economies and Policy Studies, Massey University, p. 11.

10. Elasticidad-renta de la demanda es la variación porcentual que experimenta la cantidad demandada cuando aumenta la renta $1 \%$. Un bien de lujo tiene una elasticidad-renta de la de- 
Esto quiere decir que para el caso de los lácteos en China, a medida que las cantidades del ingreso se incrementen, habrá un aumento en las cantidades de la demanda de estos productos, proporcionalmente mayor.

$\mathrm{Si}$ bien es cierto que se han registrado incrementos porcentuales importantes en el consumo de leche en China, la realidad es que el consumo per cápita individual es muy bajo y muy lejos de alcanzar el consumo mínimo recomendable por la Organización Mundial de la Salud (OMS), la cual establece que para que una persona se desarrolle en condiciones aceptables, debería consumir como mínimo 150 litros por año, es decir, aproximadamente 410 mililitros por día, y como mencionamos anteriormente, en 2007 el consumo per cápita en China fue de 21 litros en promedio, es decir, aproximadamente 6 mililitros por día de los 410 recomendados por la oms. Por esta razón, en general, la principal fuente de calorías y proteínas en la dieta de los chinos continúa basándose en cereales, verduras y frutas; asimismo, la carne de puerco es la preferida en la dieta de los chinos. No obstante, como se mencionó, aunque los chinos cada vez consumen más leche, este incremento es poco significativo si se compara con países desarrollados, sin embargo, es posible considerar como relevante este crecimiento en el consumo, sobre todo si se analizan los últimos 25 años. Por ejemplo, en 1975 el consumo per cápita era de 1.19 litros por persona al año; en 2000 fue 6.7 litros y en 2007, 21 litros, de acuerdo con datos de la FAO. Esto quiere decir que de 2000 a 2007, en China se ha registrado una tasa de crecimiento promedio anual en el consumo de leche de $21.8 \%$; esto quiere decir también que en el año 2007 los chinos consumieron tres veces la leche que consumieron en 2000.

Otro de los aspectos que llama la atención en China es el hecho de que, a medida que se incrementa el nivel de consumo de leche entre su población, le sigue a su vez un incremento en la producción aún más dinámico; es decir, no obstante que el crecimiento en el consumo casi se cuadruplicó de 2000 a 2007 (al pasar de 10.7 mil millones de litros a 37.8 mil millones de litros consumidos), el índice de autosuficiencia en leche ha aumentado en esos mismos años, ya que en el año 2000 , China producía $80.5 \%$ de su consumo y en 2007 produjo casi $94 \%$. Este crecimiento que se ha venido mostrando en la producción interna se debe en gran parte a un incremento en el hato

manda mayor que 1 , un bien necesario tiene una elasticidad renta de la demanda menor que 1. Si la elasticidad-renta de la demanda es mayor que 1 , un aumento de la renta de $1 \%$ eleva la cantidad demandada más de $1 \%$, manteniéndose todo lo demás constante. 


\section{Cuadro 5}

Consumo diario de leche por persona (equivalente en litros)

\begin{tabular}{llll}
\hline País & 2005 & 2006 & 2007 \\
\hline China & 0.06 & 0.07 & 0.06 \\
India & 0.09 & 0.09 & 0.09 \\
Australia & 0.77 & 0.67 & 0.76 \\
Francia & 0.90 & 0.90 & 0.90 \\
Estados Unidos & 0.69 & 0.70 & 0.70 \\
Japón & 0.21 & 0.20 & 0.21 \\
México & 0.32 & 0.31 & 0.32 \\
\hline
\end{tabular}

Fuente: elaborado con datos de la FAO.

ganadero (que fue de $153.8 \%$ del año 2000 al 2007), y en menor medida, a un incremento en la productividad basado en un mayor rendimiento por unidad animal. De acuerdo con cifras de producción y del hato ganadero, en 2000 la producción por unidad animal promedio nacional fue de 4.8 litros por día y en 2007, de 7.8 litros por día; es decir, se registró un crecimiento en el rendimiento de $62 \%$.

Otra característica del consumo de leche en China es que éste no se da de manera uniforme en todo el país y las diferencias en el consumo entre unos lugares y otros son muy extremas. Por ejemplo, de acuerdo a un estudio en el año 2000, en las áreas urbanas los rangos de consumo oscilaban de entre cero a 24 litros por persona al año, y en las áreas rurales el rango iba de cero a catorce litros. En las áreas urbanas donde se registró un mayor consumo fueron Pekín y Shanghai; también existieron regiones rurales donde se consumía leche por arriba del promedio, como en las provincias lejanas de occidente (Xinjiang, Qinghai y el Tibet), regiones que son habitadas en su gran mayoría por minorías. ${ }^{11}$

Aunque los chinos cada vez están más convencidos de que consumir leche es saludable por su elevado valor nutricional, también hay creencias que se contraponen a esta idea, sobre todo en zonas rurales; por ejemplo, en estos lugares la leche es considerada como un alimento caliente que debería consumirse en forma moderada (otro alimento caliente es el pollo frito). De acuerdo con la tradición, consumir en exceso estos alimentos puede

11. Wattiaux, Michel A., op. cit., p. 25. 


\section{Cuadro 6}

Indicadores de leche bovina en China (equivalente a millones de litros)

\begin{tabular}{lrrrrc}
\hline Año & Producción & Importación & Exportaciones & Consumo & $\begin{array}{c}\text { Autosuficiencia } \\
\text { en leche } \%\end{array}$ \\
\hline 1990 & 4,362 & 1,002 & 28 & 5,336 & 81.75 \\
1991 & 4,874 & 1,097 & 30 & 5,941 & 82.04 \\
1992 & 5,278 & 1,032 & 48 & 6,262 & 84.29 \\
1993 & 5,264 & 1,048 & 72 & 6,240 & 84.36 \\
1994 & 5,577 & 1,388 & 57 & 6,908 & 80.73 \\
1995 & 6,082 & 1,303 & 82 & 7,303 & 83.28 \\
1996 & 6,610 & 1,285 & 71 & 7,824 & 84.48 \\
1997 & 6,341 & 1,584 & 111 & 7,814 & 81.15 \\
1998 & 6,959 & 1,531 & 126 & 8,364 & 83.20 \\
1999 & 7,514 & 1,909 & 132 & 9,291 & 80.87 \\
2000 & 8,632 & 2,245 & 163 & 10,714 & 80.57 \\
2001 & 10,601 & 2,063 & 107 & 12,557 & 84.42 \\
2002 & 13,355 & 2,626 & 157 & 15,824 & 84.40 \\
2003 & 17,817 & 2,954 & 157 & 20,614 & 86.43 \\
2004 & 22,928 & 3,174 & 191 & 25,911 & 88.49 \\
2005 & 27,837 & 2,960 & 252 & 30,545 & 91.13 \\
2006 & 32,257 & 3,163 & 273 & 35,147 & 91.78 \\
2007 & 35,574 & 2,985 & 676 & 37,883 & 93.90 \\
\hline
\end{tabular}

Fuente: http://www.fao.org.

provocar dolor de garganta y ampollas en la boca. En contraste, el consumo de alimentos considerados fríos, como la sandía y las peras, puede provocar orina frecuente, sudoración y diarrea. Por lo tanto, además de los problemas mencionados arriba, esta serie de restricciones de tipo cultural limitan con frecuencia el consumo de leche en China. Incluso en las zonas urbanas, donde se está más expuesto a las ideas occidentales y los niveles de educación y de vida son más elevados, sólo $20 \%$ de las personas consumen con regularidad productos lácteos, y $30 \%$ ó $40 \%$ de los chinos que viven en estas zonas no consumen productos lácteos de ningún tipo. ${ }^{12}$

Además del incremento en los ingresos y el cambio de los patrones de consumo debidos al contacto occidental y a la forma de vida que se da en las

12. Ibídem, p. 26. 
ciudades, la intervención del gobierno chino en la promoción del crecimiento del consumo, también ha sido un factor importante. Por ejemplo, en junio de 2000, el ministro de agricultura chino publicó un ambicioso plan de largo plazo para la producción de leche. ${ }^{13}$ En ese año se producían poco más de 8 mil millones de litros de leche bovina, y se planteó el objetivo de incrementar la producción en 10 mil millones de litros más para el año 2005; finalmente, como lo muestran las cifras, dicho objetivo fue alcanzado y superado ampliamente, pues en lugar de producir 18,632 millones de litros en 2005, se produjeron 27,837 millones.

Este programa contrasta con la anterior política en la que, por mucho tiempo, el gobierno apoyó el punto de vista de que el consumo de leche debía estar reservado exclusivamente para los niños, los enfermos y personas adultas. Sin embargo, en años recientes, el gobierno ha procurado incrementar no sólo la producción sino también el consumo de leche. Por ejemplo, se han lanzado campañas extensivas en los medios donde se informa a la población que es importante que incorporen a su dieta el consumo de leche, destacando la deficiencia del calcio en la mayoría de los chinos y los problemas relacionados con esta deficiencia.

Otro programa importante del gobierno chino fue el que aplicó el ministro de agricultura con el fin de estimular el consumo de leche en las escuelas (Programa de Leche Escolar). Este programa fue puesto a prueba en 1999 en cinco grandes ciudades (Pekín, Shanghai, Tianjin, Shenyang y Guangzhou) y a partir del 15 de noviembre de 2000 ha sido implementado en todo el país. Se espera que este programa - al parecer exitoso- contribuya de manera significativa en el crecimiento de la demanda de leche y productos lácteos, en el mediano y largo plazo. ${ }^{14}$ Según un estudio internacional realizado por Griffin y publicado en 2000, los niños que regularmente toman leche y consumen productos lácteos tienden a continuar haciéndolo como adultos, porque los hábitos alimenticios adquiridos en la niñez persisten en la edad adulta. ${ }^{15}$

Además del interés mostrado por el gobierno mediante campañas publicitarias a través de los medios de comunicación, con el fin de que la población consuma leche de manera regular, resaltando los beneficios para la salud, también hay detractores que cuestionan estos beneficios que se podrían obtener

13. Ídem.

14. Zhang-Yue Zhou, op. cit., p. 14.

15. Wattiaux, Michel A., op. cit., p. 27. 
por un mayor consumo de leche. Por ejemplo, el Departamento de Agricultura de Estados Unidos (USDA, por sus siglas en inglés) en 1995 puntualizó que la carne y la leche no son necesarias en la alimentación humana. ${ }^{16}$ Otros señalan que mientras son claros los beneficios que se obtienen al consumir leche, también existen potenciales inconvenientes si se consume en demasía.

Debido a lo que está sucediendo en China, Derek Yach, director ejecutivo de enfermedades crónicas de la organización Mundial de la Salud (wHO, por sus siglas en inglés), señaló que las generaciones más viejas en China se habían beneficiado por una dieta basada en un alto consumo de verduras y frutas y un bajo consumo en grasas, y que al cambiar estos hábitos alimenticios hacia un mayor consumo de leche podría deshacer estos beneficios que se habían conseguido con anterioridad. ${ }^{17}$ Finalmente, Colin Campbell, profesor de bioquímica alimenticia en Cornell y director del proyecto Cornell-China-Oxford (el más extenso jamás realizado sobre el régimen alimenticio y enfermedades), dijo que si los productos lácteos son consumidos junto con una alta dieta basada en proteína animal, cualquier potencial beneficio por el incremento en la densidad de los huesos podría ser indeterminado. Lo anterior debido a que la proteína animal, incluyendo la que proviene de los lácteos, podría extraer más calcio de los huesos del que fuera asimilado con un mayor consumo de leche. Este fenómeno podría explicar el hecho de que los estadounidenses que ingieren cantidades mayores de calcio, tienen índices de osteoporosis y de fractura de cadera más elevados, comparado con muchos chinos y otros asiáticos que consumen pocos productos lácteos y bajos montos de calcio. Campbell dijo que las fracturas de cadera en Estados Unidos, por ejemplo, ocurren aproximadamente cinco veces más que en China. ${ }^{18}$

Finalmente, en cuanto al comercio de las importaciones de leche, debido al crecimiento del consumo, aunque éstas han crecido, no lo ha hecho al ritmo que se esperaba, esto se debe principalmente a que, a medida que se incrementa el consumo de leche en China, este crecimiento ha sido acompañado por una dinámica mayor en la producción, es decir, se ha tratado de cubrir este incremento de la demanda interna con un incremento en la producción nacional. En términos de valor, en 2007 la importación de lácteos fue de 1,197

16. Goodland, Robert, op. cit., p. 3.

17. Chen, Kathy, "Got milk? The new craze in China is dairy drinks", en: http://www.mindfully. org/Food/2003/China-Dairy-Drinks28feb03.htm,

18. http://www.news.cornell.edu. 
millones de dólares, y equivalieron a casi 3 mil millones de litros de leche. Por su parte, las exportaciones en ese mismo año fueron de 297 millones de dólares, equivalentes a 676 millones de litros. Por otra parte, la gran mayoría de las exportaciones que realiza China, tienen como destino Hong Kong y Taiwán.

Cuadro 7

Comercio de lácteos en China (millones de dólares)

\begin{tabular}{cccc}
\hline Año & Importaciones & Exportaciones & Saldo \\
\hline 1990 & 307 & 13 & -294 \\
1991 & 333 & 16 & -317 \\
1992 & 343 & 22 & -321 \\
1993 & 337 & 28 & -309 \\
1994 & 350 & 24 & -326 \\
1995 & 379 & 35 & -344 \\
1996 & 372 & 33 & -339 \\
1997 & 438 & 45 & -393 \\
1998 & 337 & 47 & -290 \\
1999 & 398 & 53 & -345 \\
2000 & 438 & 62 & -376 \\
2001 & 468 & 45 & -423 \\
2002 & 456 & 61 & -395 \\
2003 & 535 & 56 & -479 \\
2004 & 664 & 79 & -585 \\
2005 & 707 & 109 & -598 \\
2006 & 805 & 120 & -685 \\
2007 & 1197 & 297 & -900 \\
\hline
\end{tabular}

Fuente: http://www.fao.org.

Para los países que son exportadores netos de productos lácteos resulta estimulante el creciente consumo de lácteos en China y el aumento de sus importaciones. Entre los principales productos lácteos importados y sus principales proveedores en 2005, según datos de la FAO fueron, para el caso de leche en polvo, Nueva Zelanda con una participación de $77 \%$ del total; en el caso de suero, Estados Unidos fue su principal proveedor con $40 \%$ del total, y finalmente, 73 \% de la leche líquida había sido importada de Australia. 


\section{Conclusión}

Por el tamaño de su población, China podría ser en el futuro un mercado potencial muy importante para los países que son exportadores de estos productos, esto se debe a que en los últimos años se ha presentado un dinamismo muy importante en su consumo que - como lo mencionamos anteriormente- obedece a varias razones como son: el creciente nivel de ingresos de su población, una activa participación del gobierno en la promoción del consumo, así como por la influencia que tienen las campañas informativas que inducen a la población a que consuma más leche y de manera constante. Por otro lado, también es cierto que son estos mismos niveles crecientes en el consumo los que podrían ocasionar un aumento importante en los precios internacionales de la leche, y este resultado, para el caso de países que son importadores netos ${ }^{19}$ de leche, como es el caso de México, no son buenas noticias puesto que significa un mayor gasto y una mayor salida de divisas.

Por otra parte, así como se ha incrementado el consumo y las importaciones de lácteos en China, también se observa un aumento importante en su producción, que de hecho ha permitido reducir la dependencia alimentaria de lácteos en China. Por esta razón, es probable que la prioridad en la política del gobierno chino se centre en el crecimiento de su industria lechera, más que pensar en una continua dependencia de sus importaciones; es decir, bajo su ambicioso plan de modernización, China probablemente priorizará sus importaciones de industrias clave como las de energía, electrónica, transporte y comunicación. ${ }^{20}$ Si esto es así, lo que pareciera ser un mercado potencial muy importante, tal vez no lo sea, al menos en la proporción que se esperaría dado el tamaño de su población y el creciente nivel de ingresos.

Además de lo anterior y debido a otras dos razones como el hecho de que los cambios en los patrones de consumo de un país suceden de manera gradual, es decir, no son de un día para otro, y que probablemente se esté llegando al tope de consumo, dado que, tradicionalmente, los países asiáticos no se han caracterizado por ser grandes consumidores de leche, se puede concluir también que el incremento en la importación de lácteos de China se mantenga a un nivel moderado en el futuro. mis

19. Un importador neto de lácteos es aquel país cuyas compras por concepto de importación de lácteos son superiores a las ventas por concepto de exportación de lácteos.

20. Wattiaux, Michel A., op. cit., p. 28. 


\section{Relaciones México-Japón}

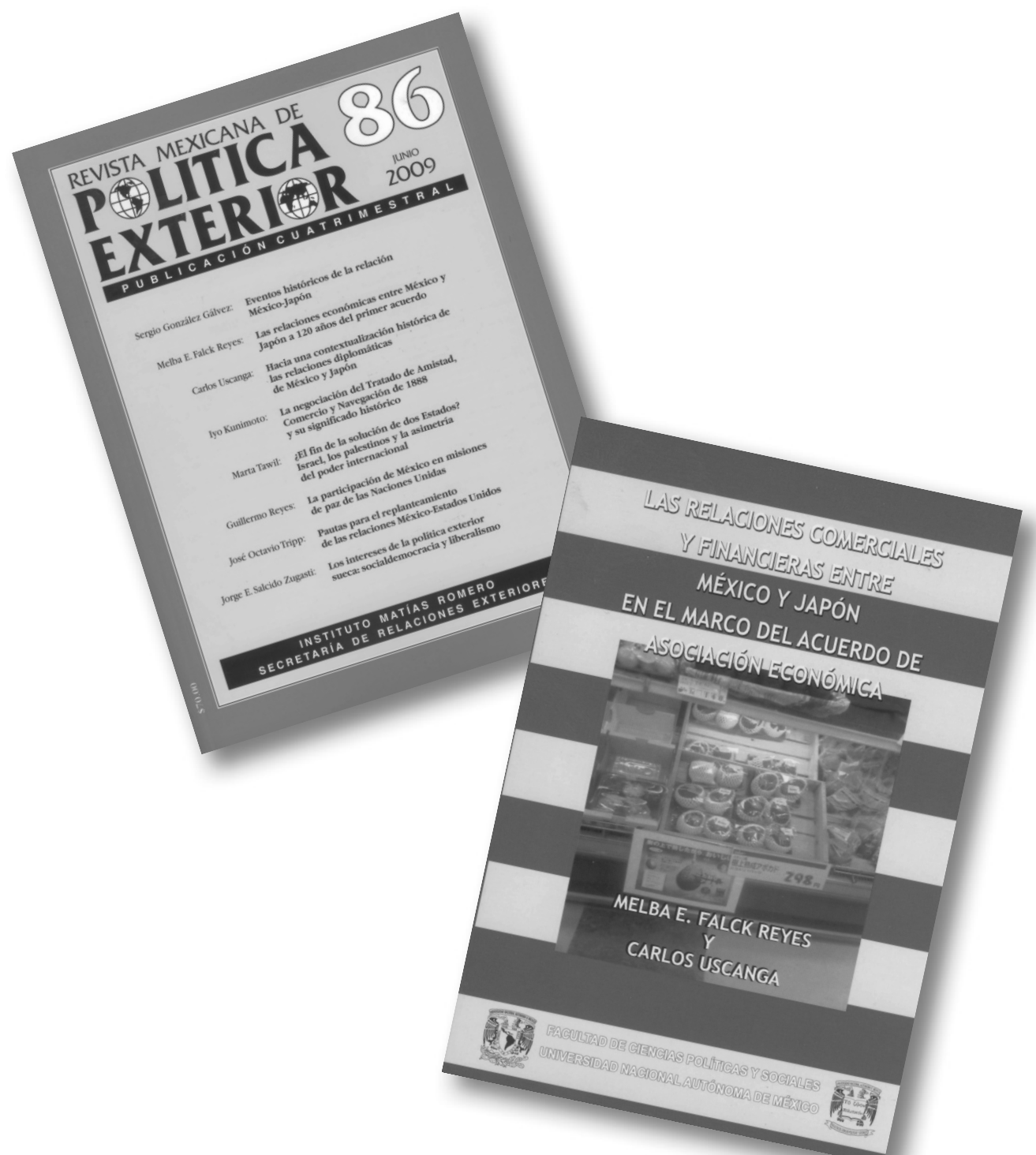

